\title{
Australian Journal of \\ In vitro antifungal activity of Desmodium intortum and D. uncinatum root extracts against growth of toxigenic Fusarium verticillioides and Aspergillus flavus
}

\author{
Nancy Karimi Njeru ${ }^{1,2} *$, Charles Aura Odhiambo Midega ${ }^{1}$, James Wanjohi Muthomi ${ }^{2}$, John Maina \\ Wagacha $^{3}$, Zeyaur Rahman Khan ${ }^{1}$
}

\author{
${ }^{1}$ International Centre of Insect Physiology and Ecology (icipe), Mbita, Kenya \\ ${ }^{2}$ Department of Plant Science and Crop Protection, University of Nairobi, Kenya \\ ${ }^{3}$ School of Biological Sciences, University of Nairobi, Kenya
}

\section{*Corresponding author: kariminancyn@gmail.com}

\begin{abstract}
Maize grown under push-pull cropping system has been reported to contain lower concentrations of fumonisin and aflatoxin than maize monocrop. This study determined the inhibitory effect of desmodium root extracts on spore germination and radial growth of toxigenic Aspergillus flavus and Fusarium verticillioides. Aspergillus flavus and $F$. verticillioides were isolated from maize and soil and tested for ability to produce aflatoxin and fumonisin by inoculation on mycotoxin-free maize. Aflatoxin and fuminisin were detected and quantified by direct competitive ELISA. Desmodium roots were dried, ground to fine powder and extracted with methanol and dichloromethane and evaluated for anti-fungal activity by inhibition of spores of $A$. flavus and $F$. verticillioides potato dextrose agar (PDA) medium. Isolates of $F$. verticillioides produced up to $599,741 \mu \mathrm{g} / \mathrm{kg}$ fumonisin while isolates of $A$. flavus produced up to $199,184 \mu \mathrm{g} / \mathrm{kg}$ aflatoxin. Desmodium root extracts reduced germination of $A$. flavus spores and $F$. verticillioides by $9.6 \%$ and $43.8 \%$, respectively and reduced their respective colony radial growth by $15 \%$ and $57 \%$. The results suggested that desmodium roots contain chemical compounds that inhibit growth of $A$. flavus and $F$. verticillioides. This may explain the reduction in infection of maize with mycotoxin-producing fungi before harvest in push-pull cropping systems by reducing the pathogen inoculum in the soils. Determination of the active compounds in the root exudates is recommended.
\end{abstract}

Keywords: aflatoxin; Aspergillus flavus; Desmodium; fumonisin; Fusarium verticillioides; push-pull; root extracts.

\section{Introduction}

Mycotoxins are chemical compounds produced by fungi found in soil and crop residues (Miller, 2008; Negedu et al., 2011; WHO, 2018). The amount of mycotoxin produced by a fungus is dependent on environment conditions (moisture, humidity, temperature) and available nutrients (Miller, 2008). Aflatoxins and fumonisins are the most economically important mycotoxins of maize in sub-Saharan Africa (Lewis et al., 2005; Mutegi et al., 2018; Mutiga et al., 2015). Chronic exposure to food contaminated with aflatoxin is associated with suppressed immunity in humans, liver cancer, damage of vital organs and decreased productivity (IARC, 1972; Lewis et al., 2005). Fumonisins causes health and economic hazards and it is associated with apoptosis of the liver and kidneys, pulmonary edema, esophageal cancer, neural tube birth defects and toxification of the nervous system (IARC, 1972; Olga, 2009; WHO, 2018).

Aspergillus flavus and $F$. verticillioides are the major producers of aflatoxin and fumonisin, respectively (IARC, 1972; Klich, 2007; Samson and Varga, 2009) and they are responsible for maize ear rots (Schmaile III and Munkvold, 2009). Aspergillus flavus is an opportunistic pathogen of maize and grows as yellow-green spore masses on maize grains (Schoeman, 2012) leading to deterioration of maize quality (Cotty and Jaime-Garcia, 2007). Strains of $A$. flavus differ in the amounts of aflatoxins produced, with $A$. flavus $\mathrm{S}$ strain $(<$ $400 \mu \mathrm{m}$ sclerotia diameter) producing higher levels of aflatoxin than A. flavus L strain (> $400 \mu \mathrm{m}$ sclerotia diameter) (Cotty, 1989). Fusarium verticillioides is a cosmopolitan pathogen of maize whose growth on maize is characterized by pinkish to violet moldiness on the grain (Leslie and Summerell, 2006). Although $F$. verticillioides can infect the maize plant systemically from infected seeds and through wounds caused by Lepidopteran larvae, the most efficient route of infection is through the silk (Sobek and Munkvold, 1999; Thompson et al., 2018). Fusarium verticillioides persists in host residues for up to 900 days depending on the prevailing climatic conditions (Fernandez et al., 2008).

Push-pull cropping system was reported to significantly reduces the levels of aflatoxin and fumonisin in pre-harvest maize (Njeru et al., 2019). The 'push-pull' technology involves intercropping cereals such as maize or sorghum with a fodder legume such as Desmodium and planting a fodder grass such as Napier or Brachiaria as a border around the maize-Desmodium intercrop (Cook et al., 2007; Khan et al., 2002). The Desmodium acts as the 'push' crop by producing chemicals that repel stemborer and fall armyworm moths while the Napier or Brachiaria border act as the 'pull' crop by 
attracting stemborer and fall armyworm moths away from the maize (Khan et al., 2000; Midega et al., 2018).

Plant root-exudates have been reported to influence the fungal community in the soil by maintaining the population of resident fungi and inhibiting existence of non-residence fungi (Broeckling et al., 2008; Yang et al., 2014). The relationship between soil microorganisms and plants are very specific (Boivin et al., 2016; Steinkellner et al., 2007; Sullia, 1973) and in vitro studies have demonstrated the inhibitory activity of plant extracts against fungal plant pathogens (Muthomi et al., 2017; Njoki et al., 2017; Okumu et al., 2019). The inhibitory activity could be attributed to presence of bioactive chemicals such as flavonoids and alkaloids, which suppress spore germination and modify the structure of the fungal mycelia (Tabassum and Vidyasagar, 2013). Roots of mature Desmodium produces C-glycosyl flavonoid exudates (Hooper et al., 2015). This study sought to determine the mechanisms involved in reduction of ear rots and mycotoxins in maize under push-pull cropping system. Extracts from Desmodium roots were evaluated for their activity against toxigenic $A$. flavus and $F$. verticillioides in vitro.

\section{Results}

\section{Aflatoxin and fumonisin production by Aspergillus flavus and Fusarium verticillioides}

Maize colonized by $A$. flavus and $F$. verticillioides isolates is shown in supplementary figure 1. Ninety-four (94) percent of A. flavus isolates from both push-pull and non-push-pull maize produced detectable levels of aflatoxin. There was no significant $(P=0.266)$ difference between the aflatoxin levels produced by isolates recovered from push-pull and those recovered from non-push-pull cropping systems. Aflatoxin production potential of the $A$. flavus isolates ranged from below lower limit of detection to 199,184 $\mu \mathrm{gkg}-1$ (Table 1). On the contrary, all the $F$. verticillioides isolates produced high levels of fumonisin between 2804 and 599,741 $\mu \mathrm{g} / \mathrm{kg}$ (Table 1). The fumonisin production potential did not differ between isolates from push-pull and those from non-push-pull ( $P=$ 0.757).

\section{Effect of desmodium root extracts on mycelial growth}

Crude extracts from roots of $D$. intortum and $D$. uncinatum significantly $(P<0.001)$ reduced colony radial growth of $A$. flavus and $F$. verticillioides isolates (Supplementary figure 2, Table 2). The reduction in colony radial growth was also significant across days after incubation $(P<0.05)$. Colony radial growth was significantly $(P<0.05)$ influenced by the days of incubation. Reduction of radial growth of $A$. flavus was, however, not significantly different between the extracts of $D$. intortum and $D$. uncinatum. The root extracts reduced the radial growth of $F$. verticillioides and $A$. flavus colonies by $53-61 \%$ and $12-17 \%$, respectively (Table 3 ). The percentage reduction in radial growth for most $F$. verticillioides colonies decreased with increased duration of incubation. Percentage reduction of $A$. flavus and $F$. verticillioides growth was significantly $(P<0.05)$ decreased across days of incubation. Desmodium uncinatum root extract was significantly $(P<0.05)$ more effective in reduction of $F$. verticillioides radial growth compared to $D$. intortum extract. Both $D$. intortum and $D$. uncinatum caused significantly $(P<0.001)$ more reduction in colony diameter of $F$. verticillioides than that of $A$. flavus.

\section{Effect of desmodium root extract on spore germination and germ tube growth}

Aspergillus flavus and $F$. verticillioides spores germinated after six hours of incubation and the germ tubes started developing into hyphae after 10 hours (Supplementary figure 3, Supplementary figure 4). The Desmodium root extracts significantly $(P=0.001)$ reduced the proportion of germinated spores of $A$. flavus after ten hours of incubation (Table 4, Supplementary figure 3 ). The number of germinated $A$. flavus spores was reduced by $3.2-11.4 \%$ while germ tube elongation was inhibited by $16.1-48.3 \%$ depending on the duration of incubation (Table 4).

The extracts significantly $(P<0.05)$ reduced the proportion of germinated $F$. verticillioides spores and length of germ tubes by up to $50.0 \%$ and $43 \%$, respectively, after six and eight hours of incubation (Supplementary figure 4, Table 4). After ten hours of incubation, over $95 \%$ of the spores in the plates treated with extracts had germinated but the germ-tubes were short and the hyphae had not started branching. However, in the control plates without extract, there was $100 \%$ spore germination after 10 hours and hyphae were fully formed and branched.

\section{Discussion}

The results of this study showed that all the $F$. verticillioides produced high amounts of fumonisin between 2804 and $599,741 \mu \mathrm{g} / \mathrm{kg}$. This indicates that under favourable environmental conditions, high amounts of fumonisins produced by $F$. verticillioides may accumulate in maize maturing in the field (Leslie and Summerell, 2006). This poses risk of toxin exposure to consumers in the study area, where maize is the main staple food. The fumonisin levels recorded in this study could be due to the ideal incubation conditions of the maize under experimental conditions. In spite of being a field toxin, high populations of $F$. verticillioides in physiologically mature maize can also lead to high levels of fumonisin during post-harvest handling and storage, especially if the maize is exposed to temperature, humidity and moisture that is favorable for proliferation of the fungus and fumonisin production (Fountain et al., 2014; Miller, 2008). Fusarium verticillioides grow and produce fumonisin at temperatures between 20 and $25^{\circ} \mathrm{C}$ at moderate water activity (Camardo Leggieri et al., 2019). Fumonisin production under field conditions is also increased by drought stress (Leslie and Summerell, 2006; Samapundo et al., 2005). These conditions are prevalent in western Kenya, where average temperature and precipitation is $18.5-22.7^{\circ} \mathrm{C}$ and 1300 toover $2000 \mathrm{~mm}$, respectively, annually (Jaetzold et al., 2009).

Unlike $F$. verticillioides, not all tested $A$. flavus isolates produced aflatoxin. Six percent of $A$. flavus isolates did not produce aflatoxin, while $53 \%$ produced low levels of up to 10 $\mu \mathrm{g} / \mathrm{kg}$ and $41 \%$ produced between 10 and 199,184 $\mu \mathrm{g} / \mathrm{kg}$ of aflatoxin. Although $A$. flavus has been reported to occur in low frequency and abundance (Nyangi, 2016; Owuor et al., 2018), further infection and aflatoxin production could increase during handling and storage under high moisture, temperature 
Table 1. Aflatoxin levels $(\mu \mathrm{g} / \mathrm{kg})$ produced in clean maize by $A$. flavus and fumonisin levels $(\mu \mathrm{g} / \mathrm{kg})$ produced by $F$. verticillioides isolated from maize and soil under push-pull and non-push-pull cropping systems.

\begin{tabular}{|c|c|c|c|c|c|c|}
\hline \multirow[t]{2}{*}{ Range } & \multicolumn{3}{|c|}{ Fumonisin } & \multicolumn{3}{|c|}{ Aflatoxin } \\
\hline & Push-pull $(n=49)$ & Non-push-pull $(n=45)$ & Overall $(n=94)$ & Push-pull $(n=53)$ & Non-push-pull $(n=52)$ & Overall $(n=105)$ \\
\hline Minimum & $2,929.4$ & $2,803.8$ & $2,803.8$ & $<$ LOD & $<$ LOD & $<\mathrm{LOD}$ \\
\hline Maximum & $521,482.4$ & $599,740.6$ & $599,740.6$ & $199,184.3$ & $10,433.1$ & $199,184.3$ \\
\hline Median & $213,058.3$ & $143,563.7$ & $178,625.9$ & 7.2 & 4.9 & 5.1 \\
\hline
\end{tabular}

Table 2. Colony diameter $(\mathrm{cm})$ of $A$. flavus and $F$. verticillioides grown on PDA amended with root extracts from two desmodium species and PDA without extract for two, four and six days.

\begin{tabular}{|c|c|c|c|c|c|c|}
\hline \multirow[t]{2}{*}{ Fungal species } & \multirow[t]{2}{*}{ Isolate } & \multirow[t]{2}{*}{ Days incubated } & \multicolumn{2}{|c|}{ D. intortum } & \multicolumn{2}{|c|}{ D. uncinatum } \\
\hline & & & Extract & No extract & Extract & No extract \\
\hline \multirow[t]{18}{*}{ A. flavus } & $81 \mathrm{~B}$ & Two & $1.1 \pm 0.0$ & $1.4 \pm 0.1$ & $1.4 \pm 0.1$ & $1.0 \pm 0.0$ \\
\hline & & Four & $2.5 \pm 0.1$ & $3.1 \pm 0.0$ & $2.8 \pm 0.0$ & $2.6 \pm 0.0$ \\
\hline & & Six & $4.1 \pm 0.2$ & $5.3 \pm 0.0$ & $4.6 \pm 0.0$ & $4.3 \pm 0.0$ \\
\hline & 151D & Two & $1.1 \pm 0.1$ & $1.2 \pm 0.0$ & $1.3 \pm 0.1$ & $1.0 \pm 0.1$ \\
\hline & & Four & $2.5 \pm 0.2$ & $2.9 \pm 0.0$ & $2.4 \pm 0.1$ & $2.3 \pm 0.0$ \\
\hline & & Six & $4.0 \pm 0.3$ & $5.0 \pm 0.0$ & $3.9 \pm 0.0$ & $3.7 \pm 0.1$ \\
\hline & $105 \mathrm{~A}$ & Two & $1.5 \pm 0.0$ & $2.0 \pm 0.0$ & $1.9 \pm 0.1$ & $1.2 \pm 0.0$ \\
\hline & & Four & $3.5 \pm 0.1$ & $4.1 \pm 0.0$ & $2.4 \pm 0.0$ & $2.3 \pm 0.1$ \\
\hline & & Six & $5.4 \pm 0.1$ & $6.3 \pm 0.0$ & $3.8 \pm 0.1$ & $3.5 \pm 0.0$ \\
\hline & $2 \mathrm{M} 35 \mathrm{E}$ & Two & $1.2 \pm 0.0$ & $2.1 \pm 0.0$ & $1.3 \pm 0.1$ & $1.2 \pm 0.0$ \\
\hline & & Four & $3.8 \pm 0.0$ & $4.3 \pm 0.1$ & $2.8 \pm 0.0$ & $2.6 \pm 0.0$ \\
\hline & & Six & $4.6 \pm 0.0$ & $6.5 \pm 0.1$ & $4.6 \pm 0.0$ & $4.2 \pm 0.0$ \\
\hline & $379 B$ & Two & $1.4 \pm 0.0$ & $1.4 \pm 0.0$ & $1.3 \pm 0.0$ & $1.1 \pm 0.0$ \\
\hline & & Four & $2.9 \pm 0.1$ & $3.3 \pm 0.1$ & $2.8 \pm 0.0$ & $2.5 \pm 0.1$ \\
\hline & & Six & $4.8 \pm 0.2$ & $5.2 \pm 0.1$ & $4.6 \pm 0.1$ & $4.1 \pm 0.1$ \\
\hline & 479D & Two & $1.0 \pm 0.0$ & $1.2 \pm 0.0$ & $1.1 \pm 0.0$ & $1.0 \pm 0.0$ \\
\hline & & Four & $2.4 \pm 0.0$ & $2.8 \pm 0.0$ & $2.2 \pm 0.0$ & $2.1 \pm 0.0$ \\
\hline & & Six & $3.9 \pm 0.0$ & $4.5 \pm 0.0$ & $3.7 \pm 0.0$ & $3.3 \pm 0.0$ \\
\hline LSD & & & & 0.3 & & 0.3 \\
\hline$P$ value & & & & $<0.001$ & & $<0.001$ \\
\hline \multirow[t]{18}{*}{ F. verticillioides } & $561 \mathrm{~B}$ & Two & $2.1 \pm 0.0$ & $0.9 \pm 0.0$ & $0.5 \pm 0.0$ & $1.6 \pm 0.0$ \\
\hline & & Four & $4.2 \pm 0.0$ & $2.2 \pm 0.0$ & $1.3 \pm 0.1$ & $3.2 \pm 0.0$ \\
\hline & & Six & $6.7 \pm 0.0$ & $3.5 \pm 0.0$ & $2.2 \pm 0.0$ & $5.1 \pm 0.1$ \\
\hline & $552 \mathrm{~A}$ & Two & $1.8 \pm 0.0$ & $0.8 \pm 0.1$ & $0.5 \pm 0.1$ & $1.6 \pm 0.0$ \\
\hline & & Four & $3.6 \pm 0.0$ & $1.8 \pm 0.1$ & $1.4 \pm 0.0$ & $3.3 \pm 0.0$ \\
\hline & & Six & $5.4 \pm 0.0$ & $2.8 \pm 0.2$ & $2.4 \pm 0.0$ & $5.2 \pm 0.0$ \\
\hline & $581 \mathrm{~A}$ & Two & $2.0 \pm 0.0$ & $0.8 \pm 0.0$ & $0.6 \pm 0.0$ & $1.8 \pm 0.0$ \\
\hline & & Four & $3.8 \pm 0.0$ & $2.0 \pm 0.0$ & $1.2 \pm 0.0$ & $3.2 \pm 0.0$ \\
\hline & & Six & $5.6 \pm 0.0$ & $3.0 \pm 0.0$ & $2.0 \pm 0.0$ & $4.1 \pm 0.1$ \\
\hline & $538 \mathrm{~A}$ & Two & $2.0 \pm 0.0$ & $0.8 \pm 0.0$ & $0.5 \pm 0.0$ & $1.6 \pm 0.0$ \\
\hline & & Four & $3.8 \pm 0.0$ & $1.9 \pm 0.0$ & $1.2 \pm 0.0$ & $3.0 \pm 0.0$ \\
\hline & & Six & $5.7 \pm 0.1$ & $3.0 \pm 0.0$ & $1.9 \pm 0.0$ & $4.4 \pm 0.0$ \\
\hline & $519 \mathrm{~A}$ & Two & $2.0 \pm 0.1$ & $0.8 \pm 0.0$ & $0.6 \pm 0.0$ & $1.8 \pm 0.0$ \\
\hline & & Four & $4.2 \pm 0.0$ & $1.9 \pm 0.0$ & $1.4 \pm 0.1$ & $3.3 \pm 0.0$ \\
\hline & & Six & $6.6 \pm 0.0$ & $2.9 \pm 0.0$ & $2.3 \pm 0.0$ & $5.3 \pm 0.0$ \\
\hline & $601 \mathrm{~A}$ & Two & $2.0 \pm 0.0$ & $0.8 \pm 0.0$ & $0.5 \pm 0.1$ & $1.6 \pm 0.0$ \\
\hline & & Four & $4.1 \pm 0.0$ & $1.9 \pm 0.0$ & $1.4 \pm 0.0$ & $3.3 \pm 0.0$ \\
\hline & & Six & $6.6 \pm 0.0$ & $3.0 \pm 0.0$ & $2.3 \pm 0.0$ & $5.4 \pm 0.0$ \\
\hline LSD & & & & 0.3 & & 0.3 \\
\hline$P$ value & & & & $<0.001$ & & $<0.001$ \\
\hline
\end{tabular}

Table 3. Reduction (\%) in colony diameter of $A$. flavus and $F$. verticillioides isolates grown on PDA amended with root extracts of two desmodium species and incubated for two, four and six days.

\begin{tabular}{|c|c|c|c|c|c|c|c|c|}
\hline \multirow[t]{2}{*}{ Isolate } & \multicolumn{4}{|c|}{ D. intortum } & \multicolumn{4}{|c|}{ D. uncinatum } \\
\hline & Two" & Four & Six & Mean & Two & Four & Six & Mean \\
\hline \multicolumn{9}{|c|}{ A. flavus } \\
\hline $81 \mathrm{~B}$ & 21.4 & 19.4 & 22.6 & $21.1 \pm 0.4^{b}$ & 28.6 & 7.1 & 6.5 & $14.1 \pm 2.2^{b}$ \\
\hline 151D & 8.3 & 13.8 & 20.0 & $14.0 \pm 2.0^{\mathrm{d}}$ & 23.1 & 4.2 & 5.1 & $10.8 \pm 2.2^{c}$ \\
\hline $105 \mathrm{~A}$ & 25.0 & 14.6 & 14.3 & $18.0 \pm 1.2^{c}$ & 36.8 & 4.2 & 7.9 & $16.3 \pm 2.9^{\mathrm{a}}$ \\
\hline $2 \mathrm{M} 35 \mathrm{E}$ & 42.9 & 11.6 & 29.2 & $27.9 \pm 2.4^{a}$ & 7.7 & 7.1 & 8.7 & $7.8 \pm 0.3^{\mathrm{d}}$ \\
\hline $379 B$ & 0.0 & 12.1 & 7.7 & $6.6 \pm 0.0^{\mathrm{e}}$ & 15.4 & 10.7 & 10.9 & $12.3 \pm 0.7^{b c}$ \\
\hline 479D & 16.7 & 14.3 & 13.3 & $14.8 \pm 0.4^{d}$ & 9.1 & 4.5 & 10.8 & $8.1 \pm 1.1^{d}$ \\
\hline LSD & & & & 2.5 & & & & 2.2 \\
\hline$P$ value & & & & $<0.001$ & & & & $<0.001$ \\
\hline \multicolumn{9}{|c|}{ F. verticillioides } \\
\hline $561 B$ & 57.1 & 47.6 & 47.8 & $50.8 \pm 0.7^{c}$ & 68.8 & 59.4 & 56.9 & $61.7 \pm 0.8^{\mathrm{ab}}$ \\
\hline $552 A$ & 55.6 & 50.0 & 48.1 & $51.2 \pm 0.5^{b c}$ & 68.8 & 57.6 & 53.8 & $60.1 \pm 0.9^{c}$ \\
\hline $581 \mathrm{~A}$ & 60.0 & 47.4 & 46.4 & $51.3 \pm 1.0^{\mathrm{bc}}$ & 66.7 & 62.5 & 51.2 & $60.1 \pm 1.0^{b c}$ \\
\hline $538 \mathrm{~A}$ & 60.0 & 50.0 & 47.4 & $52.5 \pm 0.9^{b}$ & 68.8 & 60.0 & 56.8 & $61.9 \pm 0.7^{\mathrm{a}}$ \\
\hline $519 A$ & 60.0 & 54.8 & 56.1 & $56.9 \pm .04^{\mathrm{a}}$ & 66.7 & 57.6 & 56.6 & $60.3 \pm 0.7^{b c}$ \\
\hline $601 \mathrm{~A}$ & 60.0 & 53.7 & 54.5 & $56.1 \pm 0.4^{\mathrm{a}}$ & 68.8 & 57.6 & 57.4 & $61.2 \pm 0.8^{\mathrm{abc}}$ \\
\hline LSD & & & & 1.3 & & & & 1.5 \\
\hline$P$ value & & & & $<0.001$ & & & & $<0.001$ \\
\hline
\end{tabular}

$\mathrm{P}$ - Calculated $95 \%$ probability value, LSD - least significant difference, "hours plates inoculated plates were incubated before counting the number of germinated spores Means followed by the same letters along the same column are not significantly different. 
Table 4. Proportion (\%) of germinated spores and germ tube length $(\mu \mathrm{m})$ of $A$. flavus and $F$. verticillioides grown on PDA amended with root extracts from $D$. intortum and incubated for six, eight and ten hours.

\begin{tabular}{|c|c|c|c|c|c|c|}
\hline \multirow[t]{2}{*}{ Treatment } & \multicolumn{3}{|c|}{ 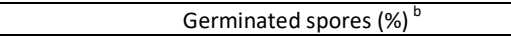 } & \multicolumn{3}{|c|}{ Germ tube length $(\mu \mathrm{m})^{* *}$} \\
\hline & $\operatorname{Six}^{* * * *}$ & Eight & Ten & Six & Eight & Ten \\
\hline \multicolumn{7}{|l|}{ A. flavus } \\
\hline Extract & $8.2 \pm 1.6$ & $32.3 \pm 2.9$ & $86.2 \pm 3.0$ & $3.3 \pm 0.3$ & $9.4 \pm 0.6$ & $23.0 \pm 3.3$ \\
\hline No extract & $8.5 \pm 1.3$ & $37.7 \pm 3.0$ & $97.3 \pm 1.7$ & $3.9 \pm 0.6$ & $11.4 \pm 0.9$ & $44.5 \pm 4.4$ \\
\hline Reduction (\%) & 3.2 & 14.2 & 11.4 & 16.1 & 17.6 & 48.3 \\
\hline$P$ value & 0.913 & 0.392 & 0.001 & 0.219 & 0.099 & 0.017 \\
\hline \multicolumn{7}{|l|}{ F. verticillioides } \\
\hline Extract & $5.9 \pm 0.9$ & $43.2 \pm 3.9$ & & $10.7 \pm 1.2$ & $21.3 \pm 1.4$ & \\
\hline No extract & $9.4 \pm 2.2$ & $86.4 \pm 2.5$ & & $14.1 \pm 1.2$ & $37.4 \pm 2.1$ & \\
\hline Reduction (\%) & 37.5 & 50.0 & & 24.1 & 43.1 & \\
\hline$P$ value & 0.021 & $<0.001$ & & 0.044 & $<0.001$ & \\
\hline
\end{tabular}

and humidity (Fountain et al., 2014). Aspergillus flavus is favored by hot and dry climatic conditions characterized by temperatures of $25-42^{\circ} \mathrm{C}$ and low moisture content, but the optimum temperature for aflatoxin production is $28-30^{\circ} \mathrm{C}$ at high water activity (>0.95) (Camardo Leggieri et al., 2019; Sanchis and Magan, 2004). Under field conditions, A. flavus is an opportunistic pathogen that infects maize weakened by factors such as drought stress, nutrient stress and physical damage (Abbas et al., 2006; Pitt and Hocking, 2006; Klich, 2007).

Root extracts of both $D$. intortum and $D$. uncinatum exhibited antifungal activity against $F$. verticillioides and $A$. flavus as demonstrated by the significant reduction in radial growth of the fungal colonies. The effect was, however, significantly higher against $F$. verticillioides compared to A. flavus. Previous studies reported reduced incidence of ear rots in maize under push-pull cropping (Owuor et al., 2018) and lower levels of mycotoxins, especially aflatoxin and fumonisin (Njeru et al., 2019). Therefore, the higher activity against $F$. verticillioides could be responsible for the observed higher reduction in the amounts of fumonisin produced on maize compared to aflatoxin as reported by (Njeru et al., 2019). However, the difference in activity between the extracts of Desmodium $D$. intortum and $D$. uncinatum cannot emphasized because the extracts were used in crude state. The inhibition of radial growth of the fungal pathogen colonies can be explained by the reduce spore germination, inhibition of germ tube and hyphae elongation observed in the in vitro experiments. Although several mechanisms by which push-pull cropping system controls the mycotoxigenic fungi and associated mycotoxins in maize have been proposed (Njeru et al., 2019), the findings of the current study imply inhibition of spore germination and mycelial growth of toxigenic $A$. flavus and $F$. verticillioides in soil as the mechanism by which the Desmodium in the cropping reduce the populations of the fungi and subsequently infection of maize with ear rots and the levels of associated mycotoxins. To our knowledge, there are no previous studies reporting on antifungal activity of $D$. intortum and $D$. uncinatum root extracts against plant pathogens, but, leaf extracts of $D$. heterocarpon have been reported to have antifungal activity against some fungi, including A. niger (Arora et al., 2014).

The two Desmodium spp. used in this study have been shown to suppress striga in push-pull cropping systems. The mechanism involved in striga suppression is through production of root exudates that contain several C-glycosyl flavonoids into the rhizosphere, which have been associated with suicidal germination of striga weed (Hooper et al., 2015). Some glycosylated flavonoids of other plants have also been associated with antifungal self-defense of mango fruits against decay-causing fungal pathogens (Sudheeran et al., 2019). (Tapas et al., 2008) and (Babu et al., 2016) reported that some groups of C-glycosyl flavonoids extracted from plant roots are active against certain fungi. Therefore, it is possible that some of the flavonoids and alkaloids in Desmodium root exudates released into the soil suppress the growth of $F$. verticillioides and $A$. flavus. The Desmodium root extracts used in this study possibly contain some of the constituents found in the root exudates released into the soil under natural field conditions. The root extracts from the roots of Desmodium were found to suppress colony growth and spore germination of $F$. verticillioides and $A$. flavus. The observed reduction in radial growth of the fungal colony could be attributed to inhibition of spore germination and modification of the structure of the fungal mycelia as a result of alteration of cell wall, cell membrane and inhibition of respiration (Tabassum and Vidyasagar, 2013). This is caused by interferences with metabolic processes such as electron transport and nutrient absorption and may lead to cell death (Chen et al., 2018; Ren et al., 2020). The functioning of cell membranes is disrupted through interruption of ergosterol content of the cell membranes, while respiration is disrupted by interruption of NADH oxidase and SDH activities of the process. It has also been reported that some plant extracts antifungal activity is through reduction in expression of mycotoxigenic genes in their biosynthesis pathway (Hu et al., 2017).

Antifungal compounds in plant extracts have been used mainly as foliar application (Muthomi et al., 2017a; Muthomi et al., 2017b) and in such cases, the active compounds require to be formulated and commercialized as bio-fungicides. The foliar fungicides work though contact or systemically once sprayed on the crops. However, in push-pull cropping systems, the active compounds in desmodium root exudates may not require extraction and formulation because they are released directly into the soil where they inhibit proliferation of mycotoxin-producing fungi. Thus in the push-pull cropping system, the root exudates reduce the primary inoculum of the mycotoxin producing Aspergillus and Fusarium in the soil resulting in reduced ear rot infection and low levels of mycotoxin in maize. Desmodium leaf extracts have also have been reported to possess antifungal activity against toxigenic fungi such as $A$. flavus and $F$. verticillioides (Mahesh and Satish, 2008). Therefore, the Desmodium plants in the push-pull cropping system possibly have additional mycotoxin-producing fungi suppression benefits through the leaves and foliage that falls and decompose, thus inhibiting proliferation of $A$. flavus and $F$. verticillioides. The decomposing residues also encourage the multiplication of beneficial microorganisms that 
may also contribute to the suppression of the pathogenic fungi.

\section{Materials and Methods}

Determination of aflatoxin and fumonisin production potential of Aspergillus flavus and Fusarium verticillioides

Aspergillus flavus and F. verticillioides were isolated from maize and soils in push-pull and non-push-pull farms. Fifty three (53) isolates of $A$. flavus were from push-pull farms while 52 isolates were from non-push-pull farms. Fusarium verticillioides isolates tested comprised of 49 isolates from push-pull and 45 isolates from non-push-pull farms.. Of the $A$. flavus tested, 21 isolates were from soil and 84 were from maize, while all the $F$. verticillioides isolates were from maize. The isolates were tested for mycotoxin production on autoclaved mycotoxin free maize grains. The maize had been tested for aflatoxin and fumonisin by direct competitive Enzyme Linked Immuno-Sorbent Assay (ELISA) (Helica Biosystems Inc., Santa Ana, USA) following manufacturer's instructions. Inoculum of each of the $F$. verticillioides and $A$. flavus isolates was separately inoculated on $20 \mathrm{~g}$ of the sterile maize grain in $40 \mathrm{ml}$ glass vials by adding $500 \mu \mathrm{l}$ of fungal suspension adjusted to $10^{8}$ spores per $\mathrm{ml}$ under aseptic conditions. The cultures were incubated at $25^{\circ} \mathrm{C}$ for seven days.

The colonized maize grain was blended with $100 \mathrm{ml}$ of $70 \%$ methanol for $A$. flavus and $40 \mathrm{ml}$ of $90 \%$ methanol for $F$. verticillioides isolates. After settling, the supernatant was passed through Whatman No. 1 filter paper and the filtrate was used for detection and quantification of aflatoxin and fumonisin by direct competitive ELISA for the A. flavus and $F$. verticillioides isolates, respectively. The lower and the upper limits of detection for the aflatoxin kits were 1 and $20 \mu \mathrm{g} / \mathrm{kg}$, respectively, while the corresponding limits for fumonisin kits were 100 and $6000 \mu \mathrm{g} / \mathrm{kg}$, respectively. Samples with mycotoxin levels above the limit of detection were diluted and the toxin levels quantified again, with consideration of the additional dilution factor in the interpretation of the results.

\section{Preparation of desmodium root extracts}

Fresh roots of $D$. intortum and $D$. uncinatum were collected from push-pull cropping system demonstration plots at the International Centre of Insect Physiology and Ecology (icipe) at Thomas Odhiambo Campus Mbita campus. The roots were washed under running tap water, chopped into one-centimeter pieces, followed by surface sterilization in $1.3 \%$ sodium hypochlorite and rinsed with distilled water. The roots were air-dried in the laboratory for one week and finely ground in a blender (Mika MNB1001 - Nutriblast Blender, $900 \mathrm{~W}-$ Black). Two hundred grams of the ground desmodium roots was extracted with $1000 \mathrm{ml}$ of dichloromethane: methanol $(1: 1 \mathrm{v} / \mathrm{v})$ by soaking and frequently shaking the mixture for 48 hours. The extract was passed through cotton wool and filtered through Whatman No.1 filter paper. The filtrate was concentrated in vacuum rotary evaporator (Stuart, $\mathrm{RE} 400 / \mathrm{CO}, \mathrm{SA})$ to $100 \mathrm{ml}$ and the concentrated extract was stored in a refrigerator at $8^{\circ} \mathrm{C}$ until use.
Determination of the effect of the desmodium root extracts on mycelial growth of toxigenic Aspergillus flavus and Fusarium verticillioides

Six of each of the aflatoxin and fumonisin producing isolates from push-pull and non-push-pull farms were randomly selected and purified on PDA medium and incubating for 48 hours at $25^{\circ} \mathrm{C}$. Spores from seven-day old cultures were used to test the antifungal activity of desmodium root extracts.

The ability of the desmodium roots extract to inhibit fungal growth was tested using poisoned food technique (Al-Samarrai et al., 2012) with modifications. The crude root extract was mixed with molten PDA cooled to $45^{\circ} \mathrm{C}$ in the ratio of one ml of methanol extract to $20 \mathrm{ml}$ media $(\mathrm{v} / \mathrm{v})$. Control PDA plates were incorporated with methanol. The PDA medium amended with root extracts was aseptically dispensed into sterile Petri-dishes and the plates were point inoculated at the center with spores from seven-day old purified cultures of toxigenic $A$. flavus and $F$. verticillioides and incubated at $25^{\circ} \mathrm{C}$. Each treatment was replicated thrice and the experiment was repeated twice. Diameters of the fungal colonies were measured at the second, fourth and sixth day after incubation. Antifungal activity was determined as inhibition of radial mycelial growth of the fungal colonies by calculating the percentage reduction in fungal radial growth as follows:

$\%$ Inhibition $=\frac{(\mathrm{dc}-\mathrm{dt})}{\mathrm{dc}} \times 100$

Where dc was the diameter of the fungal colony without extract, and dt was diameter of fungal colony in the plates with extract

Determination of the effect of desmodium root extracts on Aspergillus flavus and Fusarium verticillioides spore germination and germ tube growth

Spores of $A$. flavus and $F$. verticillioides cultured on PDA were harvested from seven-day old cultures by adding five $\mathrm{ml}$ of $0.1 \%$ Tween $80(\mathrm{v} / \mathrm{v})$ solution into the plates. The spore suspension was serially diluted to $10^{2} / \mathrm{ml}$ spore concentration and $100 \mu \mathrm{l}$ of the diluted spore suspension was spread on PDA plates amended with crude desmodium root extract in the ratio of one $\mathrm{ml}$ extract to $20 \mathrm{ml}$ media $(\mathrm{v} / \mathrm{v})$. Control plates contained PDA amended with methanol only and each treatment was replicated thrice. The media was allowed to set and the methanol to evaporate in the biosafety cabinet overnight. The plates were incubated at $25^{\circ} \mathrm{C}$ and observations made four, six, eight and ten hours after plating. A drop of lactophenol cotton blue dye was placed on the surface of the inoculated media and the number of germinated spores counted by observation under a compound microscope at $\times 400$ magnification in 10 fields of view. The length of germ tube of the germinated spores was measured using a calibrated occular micrometer. The hyphae and germ tubes were observed for growth and presence of deformities. The proportion of germinated spores was calculated using the formula

Germination $(\%)=\frac{\text { No.of germinated spores }}{\text { Total number of spores }} \times 100$

Percentage inhibition of spore germination was calculated using the formula: 
Germination inhibition $(\%)=\frac{\text { Germinated spores without extract-germinated spores with extract }}{\text { Germinated spores without }} \times 100$ Percentage inhibition of germ tube elongation was calculated using the formula: Inhibition of elongation $(\%)=\frac{\text { Germ tube length without extract-germ tube length with extract }}{\text { Germ tube length without extract }} \times 100$

\section{Data analyses}

Data on aflatoxin and fumonisin levels produced by test isolates was described using measures of central tendency in descriptive statistics procedure in SPSS version 22 (IBM Corp, 2013, New York, USA). Aflatoxin levels were categorized into below limit of detection, less than 10 and greater than 10, and association among the levels produced by isolate and cropping system from which they were isolated was determined by Chi-square test. Means of colony diameter were compared between treatments at different incubation time by Analysis of Variance (ANOVA) tested at $5 \%$ probability in $\mathrm{R}$ Studio version 3.5.3. The inhibition of spore germination, germ tube elongation and aerial growth of the fungal colonies were calculated as a percentage and compared between treatments after different hours of incubation by ANOVA. Percentage data that was not normally distributed was transformed before analysis by first changing the percentages to proportions and then using the arcsine transformation.

\section{Conclusions}

Extracts of both $D$. intortum and $D$. uncinatum inhibited germination and radial growth of toxigenic $A$. flavus and $F$. verticillioides. This implies that desmodium root extracts have potential to reduce the inocula of $A$. flavus and $F$. verticillioides in the soil, thereby preventing proliferation of the pathogens in push-pull cropping systems. The effectiveness of the root extracts was significantly higher against $F$. verticillioides than A. flavus, suggesting that desmodium would be more active in reducing Fusarium ear rots on maize. Through reduction of fungal inocula in the soil, the populations of the fungi infecting maize during growth would be reduced and consequently the levels of aflatoxin and fumonisin in maize at harvest. The findings of this study suggest that suppression of fungal inoculum in the soil is one of the mechanisms by which push-pull cropping system reduces the occurrence of maize ear rots and the associated mycotoxins. Further research on the determining the identity of the specific active compounds in the desmodium root extracts and their effect on beneficial microorganisms in soils under push-pull cropping systems is recommended.

\section{Acknowledgments}

We thank the German Academic Exchange Service (DAAD) for providing NKN with a doctoral scholarship through the ARPPIS-DAAD scholarship programme. We gratefully acknowledge the financial support for this research by the following organizations and agencies: UK's Department for International Development (DFID); European Union (EU), Biovision Foundation, Swedish International Development Cooperation Agency (Sida); the Swiss Agency for Development and Cooperation (SDC); Norwegian Agency for Development Cooperation (Norad), Federal Democratic Republic of Ethiopia; and the Kenyan Government. The views expressed herein do not necessarily reflect the official opinion of the donors.

\section{References}

Abbas HK, Zablotowicz RM, Bruns HA, Abel CA (2006) Biocontrol of aflatoxin in corn by inoculation with non-aflatoxigenic Aspergillus flavus isolates. Biocontrol Sci Techno. 16: 437-449.

Al-Samarrai G, Singh H, Syarhabil M (2012) Evaluating eco-friendly botanicals (natural plant extracts) as alternatives to synthetic fungicides. Ann Agric Environ Med. 19: 673-676.

Arora S, Yadav V, Kumar P, Kumar D (2014) Antimicrobial studies of leaf extracts from Desmodium heterocarpon (L) DC. Med Plants. 6: 206-208.

Babu BG, Naveen Kumar AD, Badana A, Kumari S, Jha A, Malla RR (2016) Effect of C-glycosyl flavone from Urginea Indica on antibiotic induced microbial cell death. Int J Pharm Pharm Sci. 8: 296-305.

Boivin S, Fonouni-Farde C, Frugier F (2016) How auxin and cytokinin phytohormones modulate root microbe interactions. Front Plant Sci. 7: 1240.

Broeckling CD, Broz AK, Bergelson J, Manter DK, Vivanco JM (2008) Root exudates regulate soil fungal community composition and diversity. Appl Environ Microbiol. 74: 738-744.

Camardo Leggieri M, Giorni P, Pietri A, Battilani P (2019) Aspergillus flavus and Fusarium verticillioides interaction: modeling the impact on mycotoxin production. Front Microbiol. 10: 2653.

Chen C, Long L, Zhang F, Chen Q, Chen C, Yu X, Liu Q, Bao J, Long Z (2018) Antifungal activity, main active components and mechanism of Curcuma longa extract against Fusarium graminearum. PLoS One. 13 https://doiorg/101371/journalpone0194284.

Cook SM, Khan ZR, Pickett JA (2007) The use of push-pull strategies in integrated pest management. Annu Rev Entomol. 52: 375-400.

Cotty PJ (1989) Virulence and cultural characteristics of two Aspergillus flavus strains pathogenic on cotton. Phytopathology. 79 : 808-814.

Cotty PJ, Jaime-Garcia R (2007) Influences of climate on aflatoxin producing fungi and aflatoxin contamination. Int J Food Microbiol. 119: 109-115.

Fernandez M, Huber D, Basnyat P, Zentner R (2008) Impact of agronomic practices on populations of Fusarium and other fungi in cereal and noncereal crop residues on the Canadian Prairies. Soil Tillage Res. 100: 60-71.

Fountain JC, Scully BT, Ni X, Kemerait RC, Lee RD, Chen ZY, Guo B (2014) Environmental influences on maize-Aspergillus flavus interactions and aflatoxin production. Front Microbiol. https://doiorg/103389/fmicb201400040.

Pitt Jl, Hocking AD (2006) Aspergillus and related teleomorphs. In food spoilage microorganisms (pp. 451-487). Woodhead Publishing. https://doi.org/10.1533/9781845691417.4.451

Hooper AM, Caulfield JC, Hao B, Pickett JA, Midega CAO, Khan ZR (2015) Isolation and identification of desmodium root exudates from drought tolerant species used as intercrops against Striga hermonthica. Phytochemistry. 117:380-387.

Hu Y, Zhang J, Kong W, Zhao G, Yang M (2017) Mechanisms of antifungal and anti-aflatoxigenic properties of essential oil derived from turmeric (Curcuma longa $\mathrm{L}$ ) on Aspergillus flavus. Food Chem. 220: $1-8$.

IARC, (International Agency for Research onCancer) (1972) IARC monographs on the evaluation of carcinogenic risk of chemicals to man CAB Direct 1, 184.

Jaetzold R, Schmidt H, Hornetz B, Shisanya C (2009) Farm management handbook of Kenya: natural conditions and farm management information, Ministry of Agriculture.

Khan ZR, Hassanali A, Overholt W, Khamis TM, Hooper AM, Pickett JA, Wadhams LJ, Woodcock CM (2002) Control of witchweed Striga hermonthica by intercropping with Desmodium spp, and the mechanism defined as allelopathic. J Chem Ecol. 28:1871-1885.

Khan ZR Pickett JA, Van Den Berg J, Wadhams LJ, Woodcock CM (2000) Exploiting chemical ecology and species diversity: stem borer and striga control for maize and sorghum in Africa, in: Pest Management Science John Wiley \& Sons, Ltd, pp 957-962.

Klich MA (2007) Environmental and developmental factors influencing aflatoxin production by Aspergillus flavus and Aspergillus parasiticus. Mycoscience. 48: 71-80. 
Leslie JF, Summerell BA, 2006 The Fusarium laboratory manual Blackwell Publishing, Oxford.

Lewis L, Onsongo M, Njapau H, Schurz-Rogers H, Luber G, Kieszak S, Nyamongo J, Backer L, Dahiye AM, Misore M, DeCock K, Rubin C (2005) Aflatoxin contamination of commercial maize products during an outbreak of acute aflatoxicosis in Eastern and Central Kenya. Environ Health Perspect. 113: 1763-1767.

Mahesh B, Satish S (2008) Antimicrobial activity of some important medicinal plant against plant and human pathogens. World J Agric Sci. 4: 839-843.

Midega CAO, Pittchar JO, Pickett JA, Hailu GW, Khan ZR (2018) A climate-adapted push-pull system effectively controls fall armyworm, Spodoptera frugiperda (J E Smith), in maize in East Africa. Crop Prot. 105:10-15.

Miller JD (2008) Mycotoxins in small grains and maize: old problems, new challenges. Food Addit Contam Part A Chem Anal Control Expo Risk Assess. 25: 219-230.

Mutegi CK, Cotty PJ, Bandyopadhyay R (2018) Prevalence and mitigation of aflatoxins in Kenya (1960-to date). World Mycotoxin J. 11: 341-357.

Muthomi J, Fulano AM, Wagacha JM, Mwang'ombe AW (2017) Management of snap bean insect pests and diseases by use of antagonistic fungi and plant extracts. Sustain Agric Res. 6: 52.

Muthomi JW, Lengai GMW, Wagacha MJ, Narla RD (2017) In vitro activity of plant extracts against some important plant pathogenic fungi of tomato. Aust J Crop Sci. 11: 683-689.

Mutiga SK, Hoffmann V, Harvey JW, Milgroom MG, Nelson RJ (2015) Assessment of aflatoxin and fumonisin contamination of maize in Western Kenya. Phytopathology. 105:1250-1261.

Negedu A, Atawodi SE, Ameh JB, Umoh VJ, Tanko HY (2011) Economic and health perspectives of mycotoxins: a review. Cont J Biomed Sci. 5: 5-26.

Njeru NK, Midega CAO, Muthomi JW, Wagacha JM, Khan ZR (2019) Influence of socio-economic and agronomic factors on aflatoxin and fumonisin contamination of maize in western Kenya. Food Sci Nutr. https://doiorg/101002/fsn31070.

Njoki LM, Okoth SA, Wachira PM (2017) Effects of medicinal plant extracts and photosensitization on aflatoxin producing Aspergillus flavus (Raper and Fennell). Int J Microbiol. https://doiorg/101155/2017/5273893.

Nyangi C (2016) Assessment of pre-harvest aflatoxin and fumonisin contamination of maize in Babati District, Tanzania. African J Food Agric Nutr Dev. 16: 11039-11053.

Okumu OO, Muthomi JW, Ojiem J, Narla R, Nderitu JH (2019) Effect of legume extracts on germination, seedling health of beans (Phaseolus vulgaris L) and soil microorganisms. Int J Plant Soil Sci. 28: 1-13.

Olga A (2009) Mycotoxins in grains harvested in 2008: Wheat. [WWW Document] Mycotoxins URL https://enengormixcom/mycotoxins/articles/mycotoxins-in-grains-h arvested-t34463htm (accessed 12119).
Owuor MJ, Midega CAO, Obonyo M, Khan ZR (2018) Impact of companion cropping on incidence and severity of maize ear rots and mycotoxins in Western Kenya. African J Agric Res. 13: 2224-2231.

Ren X, Zhang Q, Zhang W, Mao J, Li P (2020) Control of aflatoxigenic molds by antagonistic microorganisms: inhibitory behaviors, bioactive compounds, related mechanisms, and influencing factors. Toxins (Basel). 12: 1-21.

Samapundo S, Devlieghere F, De Meulenaer B, Debevere JM (2005) Effect of water activity and temperature on growth and the relationship between fumonisin production and the radial growth of Fusarium verticillioides and Fusarium proliferatum on corn. J Food Prot. 68: 1054-1059.

Samson RA, Varga J (2009) What is a species in Aspergillus? Med Mycol. 47.

Sanchis V, Magan N (2004) "Environmental profiles for growth and mycotoxin production, in: Magan, $\mathrm{N}$, Olsen, $\mathrm{M}$ (Eds), Mycotoxin in food: detection and control Woodhead Publishing Ltd, Cambridge, pp 174-189.

Schmaile DG, Munkvold GP (2009) Mycotoxi'.ns in crops: a threat to human and domestic animal health. Plant Heal Instr. Reviewed 2014 https://doiorg/101094/PHI-I-2009-0715-01.

Schoeman A (2012) Mycoctoxins- toxins produced by maize ear rot fungi [WWW Document $]$ Grain SA URL https://wwwgrainsacoza/mycotoxins---toxins-produced-by-maize-e ar-rot-fungi. (accessed 11/3/2018).

Sobek EA, Munkvold GP (1999) European corn borer (Lepidoptera: Pyralidae) larvae as vectors of Fusarium moniliforme, causing kernel rot and symptomless infection of maize kernels. J Econ Entomol. 92, 503-509.

Steinkellner S, Lendzemo V, Langer I, Schweiger P, Khaosaad T, Toussaint J, Vierheilig H (2007) Flavonoids and strigolactones in root exudates as signals in symbiotic and pathogenic plant-fungus interactions. Molecules. 12:1290-1306.

Sudheeran KP, Rinat O, Ortal G, Itay M, Noa S, Dalia M, Feygenberg O, Oren Shamir M, Alkan N (2019) Glycosylated flavonoids: fruit's concealed antifungal arsenal. New Phytol. I: 1-2.

Sullia SB (1973) Effect of root exudates and extracts on rhizosphere fungi Plant Soil. 39: 197-200.

Tabassum N, Vidyasagar GM (2013) Antifungal investigations on plant essential oils: a review Int J Pharm Pharm Sci. 5: 19-28.

Tapas AR, Sakarkar DM, Kakde RB, 2008 Flavonoids as nutraceuticals: a review Trop J Pharm Res. 7: 1089-1099.

Thompson M, Raizada M, Thompson MEH, Raizada MN (2018) Fungal pathogens of maize gaining free passage along the silk road Pathogens. 7: 81.

WHO, (World Health Organization) (2018) Mycotoxins [WWW $\begin{array}{llll}\text { Document] Fact } & \text { sheets }\end{array}$ https://wwwwhoint/news-room/fact-sheets/detail/mycotoxins (accessed 4119).

Yang X, Zhang L, Shi C, Shang Y, Zhang J, Han J, Dong J (2014) The extraction, isolation and identification of exudates from the roots of Flaveria bidentis J Integr Agric. 13: 105-114. 